\title{
ДОКУМЕНТЫ
}

\section{Правовые основы арктической политики Европейского союза}

Вылегжанин А.Н. ${ }^{*}$

Шаповалов Б.П.**

Обнародование официального текста последнего по времени документа Европейского союза (далее также - ЕС) по арктической политике ${ }^{1}$, перевод которого публикуется в настоящем номере журнала, позволяет в целом охарактеризовать современную правовую позицию Европейского союза в отношении Арктики.

К Арктическому региону в течение длительного времени «Европейский союз проявлял ограниченный интерес», вследствие чего у институтов ЕС «отсутствует систематическая информация», и они «не готовы к рассмотрению вопросов Арктики» - так отмечалось в исследовании, подготовленном в 2008 г. по заказу Северного совета министров ${ }^{2}$. Кристаллизация в международном правосознании роли Арктики в глобальном изменении климата на намей планете позволили ЕС, имеющему

\footnotetext{
* Вылегжанин Александр Николаевич - д.ю.н., профессор, член Экспертного совета по Арктике и Антарктике при Председателе Совета Федерации Федерального Собрания Российской Федерации.

** Шаповалов Борис Петрович - к.ю.н., зам. директора Центра правовых исследований СОПС при Президиуме РАН.

${ }^{1}$ European Commission High Representative of the European Union for foreign affairs and security policy. Brussels, 26.6.2012 joint (2012) 19 final. Joint communication to the European parliament and the Council. Developing a European Union Policy towards the Arctic Region: progress since 2008 and next steps $\{\mathrm{SWD}(2012) 182 \mathrm{final}\}\{\mathrm{SWD}(2012) 183 \mathrm{final}\}$ - перевод этого документа на русский язык публикуется в настоящем номере журнала.

2 The European Union and Arctic. Policies and actions. Nordic Council of Ministers, Copenhagen. 2008. P. 13.
} 
весьма разработанную природоохранную политику и ее правовые осно$b b l$, значительно повысить свой голос в международном обсуждении арктических проблем. В 1991 г. Финляндия, еще не будучи членом ЕС, дала импульс «околополюсному природоохранному сотрудничеству». После присоединения Финляндии (и Швеции) в 1995 г. к ЕС в это сотрудничество вовлекаются и органы ЕС. В 1997 г. предложено сотрудничество в рамках “Северного измерения (the Northern Dimension)», пространственный район действия которого был четко обозначен именно, только севером Европы. «Северное измерение» определено как «общие рамки для содействия диалогу и конкретному сотрудничеству, усилению стабильности, благосостоянию и устойчивому развитию на севере Европы». В такое сотрудничество вовлекались многие страны и их территории - от Исландии и Дании (Гренландия) до северо-западных территорий России, включая Мурманскую, Архангельскую, Калининградскую области. На 1-й Конференции министров иностранных дел стран «Северного измерения» в 1999 г. были обозначены главные темы сотрудничества: защита окружающей среды; устойчивое развитие; исследования в Арктике ${ }^{3}$ В 2001 г. обозначена новая инициатива - «природоохранное партнерство Северного измерения (the Northern Dimension Environmental Partnership)», нацеленная, в основном, на финансирование международной программы управления утилизацией ядерных отходов ${ }^{4}$. В 2006 г. Европейским союзом, Россией, Норвегией и Исландией была согласована «обновленная конщепџия «Северного измерения». Ее суть - «региональное выражение четырех пространств, общих для ЕС и России, с полным участием (with the full participation) в них Исландии и Норвегии», а также фокусирование внимания таких государств на вопросах «уязвимой окружающей среды, здравоохранения, социальной защиты и прав коренных народов». Что касается ссылки на «четыре пространства», то имелись в виду те, которые были обозначены в 2003 г., в рамках исполнения заключенного еще в 1997 г. Соглашения между ЕС и Россией о партнерстве и сотрудничестве: общее экономическое пространство, «включая природоохранные вопросы»; пространство для свободы, безопасности и правосудия; пространство для сотрудничества в области военной безопасности; пространство для исследования и образования, включая культурные аспекты. В 2005 г. стороны приняли «дорожные карты (road maps)»

\footnotetext{
${ }^{3}$ The European Union and Arctic... P. 18.

${ }^{4}$ Ibid. P. 20.
} 
в качестве инструментов их согласованных действий в краткосрочной и среднесрочной перспективе управления общими пространствами.

Что касается институцчиональных механизмов, в которых ЕС стремится продвигать свою природоохранную арктическую политику, то в качестве них следует указать, прежде всего, на следующие:

- Северный совет министров (Nordic Council of Ministers);

- Баренцевоморский Евроарктический совет (Barents Euro-Arctic Council);

- Арктический совет (Arctic Council).

Из этих институтов главную роль играет в настоящее время $A p \kappa m u$ ческий совет - созданный на основе Оттавской декларацчии 1996 г. форум арктических государств, квалифицируемый по одним источникам уже как международная межсравительственная организация (особенно, после создания постоянного секретариата в Норвегии), по другим как международная сессионно функционирующая конференция. В Арктическом совете участвуют 8 государств: Дания, Канада, Исландия, Норвегия, Россия, США, Швеция, Финляндия; - их национальныле организации коренных народов Севера - в качестве постоянных участников Совета: Циркумполярная конференция инуитов, Международная ассоциация алеутов, Совет саамов, Ассоциация коренных малочисленных народов Севера, Сибири и Дальнего Востока РФ и др.; - государства, пригламаемые в качестве наблюдателей; - международные организачии-наблюдатели: Комиссия ООН по окружающей среде в Европе, Совет министров Северных стран, Постоянный комитет парламентариев Арктического региона, Северный форум, Всемирный фонд природы, Международный союз охраны природы и др.

Статус постоянного наблюдателя в Арктическом Совете стремится получить и Европейский союз. ЕС в настоящее время позиционирует себя как самое влиятельное в сфере охраны арктической окружсююией cpeдbl региональное объединение государств. Вместе с тем, для ЕС сама постановка вопроса о формулировании его глобальной арктической политики - относительно новая. Из 27 государств - членов $\mathrm{EC}^{5}$ только одно - именно, Дания (из-за того, что о. Гренландия составляет часть ее государственной территории) является государством, прибрежным

\footnotetext{
5 Хотя Норвегия - не член ЕС, она участвуют в Соглашении о Европейском экономическом районе (the European Economic Area Agreement). Такая форма сотрудничества с ЕС позволяет ей применять право ЕС о внутреннем рынке с исключениями для рыбохозяйственного и сельскохозяйственного секторов экономики.
} 
$\kappa$ Северному Ледовитому океану (Arctic coastal state). Eще два государства - члена ЕС - Швеция и Финляндия - являются членами «арктической восьмерки» - то есть Арктического совета. К ним в ближайшей перспективе присоединится Исландия. Кроме того, ее гражданин избран членами Арктического Совета руководителем (директором) Секретариата Арктического Совета.

Документами ЕС, определяющими его арктическую политику, наиболее проработанными и имеющими высокий политико-правовой уровень, считаются:

- Резолюиия Европейского парламента от 30 сентября 2008 г. по управлению Арктикой.

- Сообщение Европейской комиссии Европейскому парламенту и Совету «Европейский Союз и Арктический регион» от 20 ноября 2008 2.

- Резолюиия Европейского парламента о политике ЕС в высокоширотной Арктике по ее устойчивому развитию (принята Европейским парламентом 20.01.2011 г.) / Motion for a European Parliament resolution on a sustainable EU policy for the High North, (2009/2214(INI)).

- Совместное заявление европейскому парламенту и совету «Развитие политики Европейского союза в Арктическом регионе: прогресс с 2008 года и последующие шаги» от 26 июня 2012 г.

Английское название Резолюции Европейского парламента от 30 сентября 2008 г. по управлению Арктикой - "Eигореап Parliament resolution on Arctic Governance”. Следует отметить, что это - не первый принятый Европейским парламентом документ по Арктике. Так, с 1999 г. им принято несколько резолюций о «Северном измерении». В 2005 г. Европарламент принял резолюцию о будущем «Северного измерения», в которой он, в частности призвал Европейскую комиссию воспользоваться предстоящим Международным полярным годом с тем, чтобы выдвинуть, «совместно с Арктическими партнерами», новые инициативы в направлении разработки «Хартии для управления Арктикой (Charter for Arctic Governance)». В марте 2007 г. Европарламент выступил с инициативой созвать Парламентскую конференцию по «Северному измерению». Эта конференция, в свою очередь, возобновила призыв к разработке «Хартии для управления Арктикой». Одна из групп Европарламента организовала в мае 2008 г. семинар по управлению Арктикой. Эти аккумулированные по инициативе европейских 
институтов предложения получили дальнейшее развитие в ходе Конференции, организованной Севернылм советом министров (9-10 сентября 2008 г., Илулиссат, Гренландия) ${ }^{6}$.

В таком контексте рассматриваемую резолюцию Европарламента от 30.09.2008 г. нельзя считать случайной, «непрофильной» для ЕС. В данном документе Европейский парламент, сославшись на большое число документов и международных форумов, полностью или частично посвященных арктической тематике, отметил, в частности,

- что «геополитическая и стратегическая значимость Арктического региона возрастает»;

- что «арктический регион в настоящее время не подпадает под действие каких-либо норм или правил многостороннего уровня, поскольку никогда не ожидалось, что он станет судоходным путем или районом коммерческого использования»;

- что «в последние годы интенсивность движения морских судов в Арктике значительно увеличилась вследствие возросшего интереса к бурению здесь морских недр и более частому проходу круизных судов»;

- что «Арктический регион может содержать порядка 22 процентов неоткрытых мировых запасов нефти и газа (the Arctic region may contain close to $22 \%$ of the world's undiscovered oil and gas reserves)»;

- отмечен тот факт, что «показатели глобального потепления в Арктике гораздо выше, чем в остальном мире», именно, «повышение температуры на 2 С за последние сто лет, в то время как в остальном мире этот показатель в среднем равен $0,6^{\circ} \mathrm{C}$ », и что «изменения климатических условий в Арктике привели к тому, что, например, эскимосы больше не могут охотиться традиционными способами, так как лед слишком тонок и не может выдерживать их сани, а такие дикие животные, как белые медведи, моржи и полярные лисы, находятся в опасности из-за исчезновения их естественной среды обитания»;

- что «три государства - члена ЕС являются арктическими» ${ }^{7}$, а «еще два арктических государства ... присутствуют на внутреннем рынке ЕС посредством Соглашения о Европейском экономическом

${ }^{6}$ «Common Concern for the Arctic». - Conference arranged by the Nordic Council of Ministers. Conference Report. Printed in Denmark. 2008. 166 pp.

${ }^{7}$ Имелись в виду на 2008 г. Дания, Швеция и Финляндия. К ним к настоящему времени, после положительного решения ЕС в 2010 г., присоединяется Исландия. 
пространстве» ${ }^{8}$, так что «ЕС и ассоциированные с ним государства составляют более половины числа членов Арктического Совета»;

- в тексте резолюции Европарламента акцент сделан на необходимость адекватного международного реагирования на последствия изменений климата для коренных народов Севера; подчеркнуто, что «в любые международные решения, относящиеся к этим вопросам, должны быть вовлечены народы и государства Арктики». Европарламент призвал Комиссию сформулировать «значимую Арктическую политику EC»; «поставить политику в области энергетики и безопасности в Арктике в число приоритетных вопросов повестки дня» и «рассмотреть, как ЕС и арктические государства могут работать совместно для достижения общих амбициозных целей в связи с изменением климата, устойчивым развитием, растущей безопасностью в поставках энергоносителей и более эффективным их внутренним рынком».

В числе установок, которые Европарламент сформулировал в адрес Европейской комиссии - «включить в свою повестку дня вопросы энергетической политики и политики безопасности в арктическом регионе и предложить, в частности, в своем предстоящем сообщении по этому региону соответствующие темы и процедуры совместной работы для ЕС и арктических государств в сферах изменения климата, устойчивого развития, безопасности энергоснабжения и безопасности на море»; «получить статус наблюдателя в Арктическом Совете».

Важно, что в Резолющии Европейского парламента от 9 октября 2008 года учтена Илулиссатская декларация, принятая пятью арктическими государствами (Данией, Канадой, Норвегией, Россией, Соединенными Штатами) 28 мая $2008 \Gamma^{9}$.

Вместе с тем, вопреки подходу, отраженному в Илулиссатской декларации 2008 г. пяти арктических прибрежных государств, в рассматриваемом документе Еврокомиссии предложено подготовиться «к открытию международных переговоров, направленных на принятие международного договора об охране Арктики, следуя примеру Договора об Антарктиде, дополненного Мадридским протоколом 1991 года».

Что касается второго значимого правового акта ЕС о политике в Арктике - Сообщения Еврокомиссии Европейскому парламенту и Совету

8 Имелись в виду Норвегия и, на тот период, Исландия.

9 Подробнее о большом значении этой резолюции в современном статусе Арктики см., например: Региональный уровень праворегулирования отношений государств в Арктике (комментарий). - МЖМП, № 1, 2012. С. 270-297. 
«Европейский союз и Арктический регион» от 20 ноября 2008 г., то в нем излагаются «интересы ЕС» и предлагается «государствам членам ЕС и его учреждениям принять меры, направленные на достижение трех главных целей арктической политики:

- защита и сохранение Арктики во благо ее населения,

- поощрение устойчивого использования ресурсов,

- содействие совершенствованию многостороннего управления в Арктике».

В числе перечисленных в документе предложений о таких мерах:

- Разработка новых исследовательских программ, касающихся повышения уровня моря, истончения морского льда, таяния вечной мерзлоты, а также связанных с этими явлениями последствиями, ведущими к ускоренному потеплению и оказывающими другие антропогенные воздействия на арктические экосистемы.

- Оценка состояния и эволюции развития арктической окружающей среды с целью содействия формулированию соответствующей политики ЕC.

- Создание новой научно-исследовательской инфраструктуры и расширение возможностей для мониторинга и наблюдения.

- Содействие завершению проекта по строительству исследовательского и экспериментально-промышленного ледокола «Северная Аврора».

Третий базовый документ - Резолючия Европейского парламента о политике ЕС в высокоииротной Арктике по ее устойчивому развитию (принята Европейским парламентом 20.01.2011 г.) - предусматривает, что Сообщение Комиссии от 20 ноября 2008 г. «Европейский союз и Арктический регион» является «первым официальным шагом в ответ на призыв Европейского парламента выработать политику ЕС в отношении Арктики». Отмечено, что «обращение Исландии о присоединении к ЕС приведет к тому, что ЕС необходимо будет в большей мере учитывать арктический регион в ее геополитической перспективе» и, что Норвегия, «являясь надежным партнером, связана с ЕС через Соглашение о европейском экономическом пространстве». Констатируется, что «последовательная выработка политики ЕС в отношении Арктики должна основываться на признании существующих международных, многосторонних и двусторонних договоренностей». В документе далее подчеркивается, что «определенные виды политической деятельности в отношении Арктики относятся к исключительной компетенции 
Союза, такие, например, как сохранение морских биологических ресурсов в рамках единой рыболовной политики, а также другие виды деятельности, осуществляемые совместно с государствами-членами»; что «при выработке своей политики в Арктике ЕС исходит их наилучших имеющихся научных данных и понимания процессов, затрагивающих Арктику»; что ЕС должен поводить такую политику, которая гарантирует, что при принятии мер, направленных на решение проблем окружающей среды, учитываются интересы населения арктического региона, включая его коренные народы, в области защиты и развития региона»; что необходима разработка «единой, скоординированной политики ЕС в арктическом регионе, в которой были бы четко прописаны приоритеты ЕС, потенциальные вызовы и стратегия». В таком контексте в документе отмечено «особое значение надежности и безопасности новых мировых торговых морских маршрутов в Арктике, в частности, для экономики ЕС и его государств-членов, на долю которых приходится 40 \% мировых морских перевозок». Приветствуется «работа Международной морской организации по подготовке обязательного Кодекса по судоходству в Арктике, а также ее участие в рабочих группах Арктического совета, в частности, в Целевой рабочей группе по поиску и спасанию». Подчеркивается, что «ЕС и его государствачлены должны активно отстаивать свободу морей и право свободного прохода по международным водным путям» в Арктике.

Государства региона призываются «обеспечивать положение, при котором все действующие транспортные маршруты, а также те, которые могут появиться в будущем, были бы открыты для международного судоходства, а также воздерживаться от введения каких-либо односторонних произвольных ограничений, финансовых или административных, которые бы препятствовали судоходству в Арктике, за исключением международно-согласованных мер, направленных на повышение безопасности или защиту окружающей среды».

В документе отмечена потребность в арктических природных ресурсах для растущего населения мира, признается «рост заинтересованности в них, а также суверенные права на такие ресурсы арктических государств в соответствии с международным правом». В этой связи рекомендуется «всем участвующим в такой деятельности государствам предпринять меры с целью обеспечения максимально возможной безопасности, соблюдения социальных и экологических стандартов при разведке и разработке природных ресурсов» в Арктическом регионе. 
Обращено особое внимание на тот факт, что механизмы оценки воздействия на окружающую среду «станут основными средствами управления конкретными проектами и программами в Арктике».

Весьма показательно, что в документе упоминается и о дискуссионности вопроса о толковании Договора о Шпицбергене в том, что касается его «применимости к континентальному шельфу и морским зонам» Шпицбергена. Как сказано в документе ЕС, «учитывая относительно легкую доступность ресурсов континентального шельфа» вокруг Шпицбергена, ЕС «приветствовал бы заключение соглашения о правовом статусе этого шельфа». Выражена «уверенность в том, что любые возможные споры будут решаться конструктивным образом».

Обозначена и позиция ЕС в отношении того, что до начала новых промышленных рыбных промыслов в Северном Ледовитом океане в районе за пределами 200-мильных исключительных экономических зон пяти арктических государств целесообразно проводить «научную оценку запасов рыб, исходя из принципа предосторожности, с тем, чтобы определить уровни улова, которые обеспечивали бы сохранение промысловых видов и не приводили бы к истощению запасов других видов, к серьезному ущербу для окружающей среды, и чтобы промысел любых видов в открытом море регулировался региональной организацией по управлению рыбными ресурсами, которая придерживалась бы научного подхода, располагала бы обстоятельными программами контроля и наблюдения с целью обеспечения соответствия действующим мерам управления».

В документе сказано, что «наилучшей защитной мерой для Арктики является заключение долгосрочного и далеко идущего глобального соглашения по вопросам изменения климата». При этом признается значение «институтов и общей системы международного права» в регулировании деятельности в Арктике. Отмечено, «что формируемое некоторыми обозревателями мнение, что происходит так называемая схватка за Арктику, не способствует созданию конструктивного взаимопонимания и сотрудничества в регионе» и что «арктические государства неоднократно заявляли о своей решимости урегулировать и в ряде случаев принимали меры по урегулированию возможных конфликтов интересов в соответствии с принципами международного права». Признана «роль Арктического совета как важнейшего регионального форума для сотрудничества в рамках всего Арктического региона». Сформулирован также призыв к Комиссии «в ходе переговоров 
о заключении двусторонних соглашениях принимать во внимание то обстоятельство, что чувствительная арктическая экосистема должна быть защищена, интересы населения арктического региона, включая его коренных народов, должны быть гарантированы, а использование природных ресурсов Арктики должно осуществляться на устойчивой основе». Подчеркивается то, что «ЕС и его государства-члены вносят основной вклад в проведение связанных с Арктикой научных исследований, региональное сотрудничество и развитие технологий, применительно к данному региону и за его пределами, и просит Комиссию исследовать возможности развития циркумполярного совместного финансирования и совместного программирования инициатив с тем, чтобы обеспечить более устойчивое и эффективное сотрудничество между экспертами участвующих стран». В документе содержится также призыв к «правительствам всех государств арктического региона, в частности, к Правительству России, принять и подтвердить Декларацию Организации Объединенных Наций о правах коренных народов, принятую Генеральной Ассамблеей 13 сентября 2007 г.»

Четвертылй из названных документов - принятое Еврокомиссией и ее Верховным представителем по иностранным делам и политике безопасности «Совместное заявление Европейскому парламенту и Совету». Как уже отмечено, текст этого документа переведен на русский язык и публикуется в настоящем номере журнала. В данном комментарии обозначим лишь основные направления деятельности ЕС в Арктике, как они представлены в Заявлении:

- Борьба с последствиями изменения климата. - ЕС принимает меры по реализации целей, определенных в Киотском протоколе.

- Исследования арктической экосистемы. - За последние 10 лет на проведение научных исследований в Арктике из фондов ЕС было выделено порядка 200 млн евро.

- Инвестирование в устойчивое развитие Севера. - ЕС выделяет более 1,14 млрд евро на цели развития экономического, социального и экологического потенциала Арктических регионов ЕС и прилегающих областей на 2007-2013 гг.

- Безопасность судоходства. - Почти 90\% внешней торговли ЕС осуществляется по морю, ЕС обладает значительным опытом в судоходстве, кораблестроении, спутниковой навигации, поисково-спасательных работах, а также развитии портовой инфраструктуры, внимательно следят за развитием морского транспорта в Арктике, включая 
маршруты и частоту рейсов судов по Северному морскому пути, $\mathrm{Ce}$ веро-Западному проходу и арктическим водам в целом, а также за всеми процедурами и требованиями прибрежных государств, затрагивающими международное судоходство.

- Поддержка коренных народов и местного населения. - ЕС оказывает финансовую поддержку общественным организациям, занимающимся вопросами коренных народов.

Концепция дальнейшей деятельности ЕС в Арктике определяется в документе следующими ключевыми понятиями: знание, ответственность и вовлеченность. Знание предполагает расширение знаний в сфере охраны окружающей среды, развитие диалога и усиление охраны арктической природы. Понятие «ответственность» означает, прежде всего, «финансовый вклад ЕС в развитие Арктического региона». Понятие «вовлеченность» означает, как сказано в документе, что ЕС рассматривает Арктический совет в качестве основного форума международного сотрудничества в регионе и намерен получить «статус постоянного наблюдателя в Арктическом совете». Особое внимание в Заявлении уделяется вопросу об использовании природных ресурсов Арктики. В этой связи ЕС выступает за продвижение принципов устойчивого использования природных ресурсов в таких областях, как углеводороды, иное минеральное сырье и транспорт.

В разделе Заявления, посвященном международному сотрудничеству, говорится, что постоянно развивающаяся политика ЕС в Арктике направлена на выработку последовательного и всестороннего подхода к вопросам о том, каким образом Арктический регион влияет на ЕС и наоборот. В качестве основы применимого к Северному Ледовитому океану международного права в документе ЕС - как и в документах $\mathrm{HATO}^{10}$ - названа не широкая международно-правовая база, в т.ч. международный обычай (подход пяти арктических прибрежных государств, отраженный в Илулиссатской декларации 2008 г.), а только лишь «Конвенция ООН по морскому праву» 1982 г.

В порядке краткого вывода отметим, что на первом этапе арктическая политика государств - членов ЕС, в т.ч. и природоохранная, была

${ }^{10}$ См. об этом: Международное сотрудничество в области охраны окружающей среды, сохранения и рационального управления биологическими ресурсами в Северном Ледовитом океане. Российский совет по международным делам. Гл. ред. член-корр. РАН И.С. Иванов. М. 2012 г. С. 4. 
сфокусирована, прежде всего, на отношения с Россией - государством с самым протяженным арктическим побережьем. На нынешнем этапе современный глобальный интерес самого Европейского союза к Арктическому региону - относительно новый, он обусловлен осознанием органами ЕС стержневой роли Арктики не только в глобальном изменении климата, но и в будущем мировой экономики. В соответствии с этим обновленным, растущим интересом ЕС к региону, диверсифицируются, модернизируются, детализируются правовые основы современной арктической политики Союза. Исследованные выше основополагающие документы по такой политике показывают совпадение многих оценок Россией и государствами - членами ЕС состояния и перспектив международного сотрудничества в Арктическом регионе. Вместе с тем, документы свидетельствуют и об их конкурентных интересах. Обозначены и проявившиеся различия в международно-правовых квалификациях - Европейским союзом, с одной стороны, и, с другой, пятью арктическими прибрежными государствами, при том, что одно из них является членом ЕС. 